\title{
مسجد والي باشا بمدينة يانينا (يانيه) بشمال اليونان دراسة أثرية معمارية
} أ.د/عحم حمزة إسماعيل الحداد أ.د/أحمد أمين أ.آيه عبد العزيز إبراهيم

\section{ملخص البحث}

ازدانت المدن الإسلامية بالعديد من طرز و أنماط العمائر سو اء كانت عمائر دينية أو عمائر مدنية، وقد

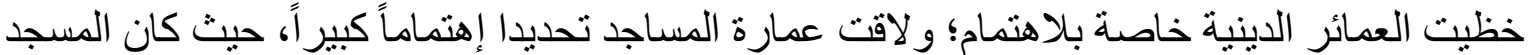
في العمائر الإسلامية يمثل النو اة للمدينة.

ولما كانت مدينة يانينا(يانيه) الواقعة بشمال اليونانو احدة من المدن الإسلامية خلال العصر العثماني

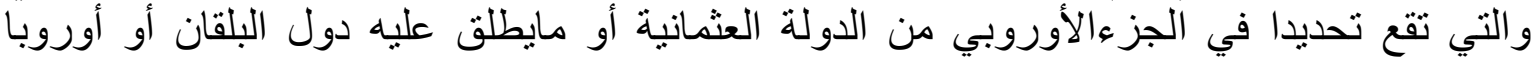

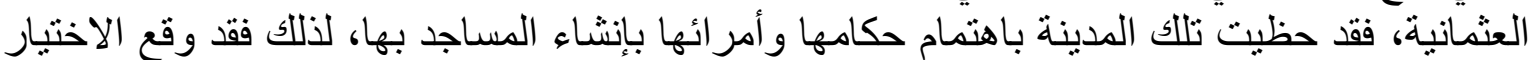

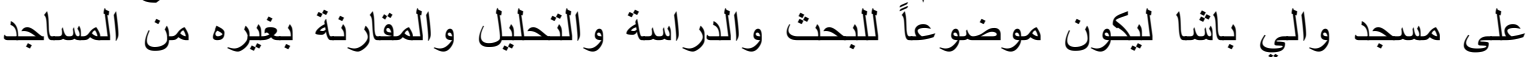

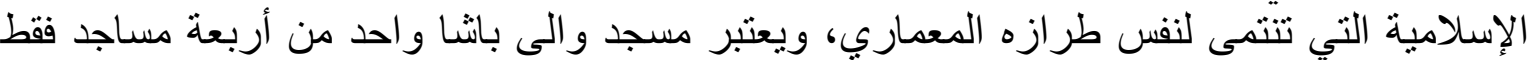

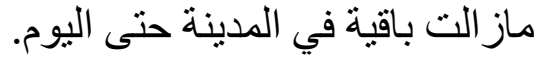

الكلمات المفتاحية:اليونان، يانيه"يانينا"، و الى باشا، مسجد، قبة

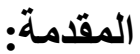

\section{لمحة تاريخية عن مدينة ياتينا (ياتيه) بشمال اليونان:}

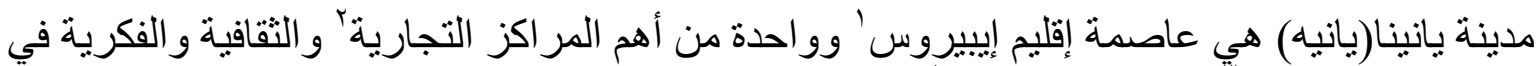

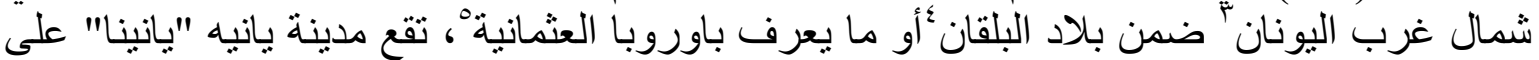

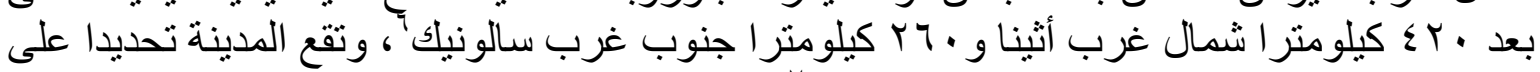

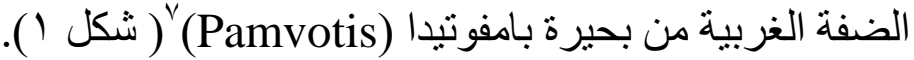

من الجدير بالذكر أنه في الوقت الحالي لم يعد يقبل الرأي السائد سابقا بأن المدينة قام بتأسيسها

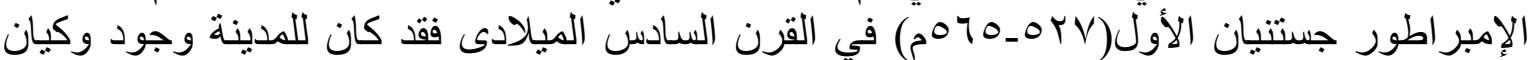

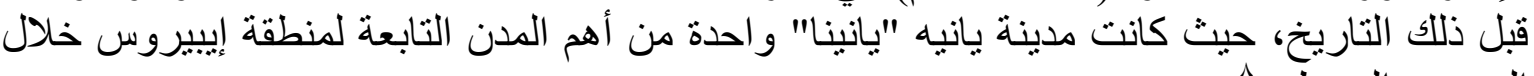
العصور الوسطي.

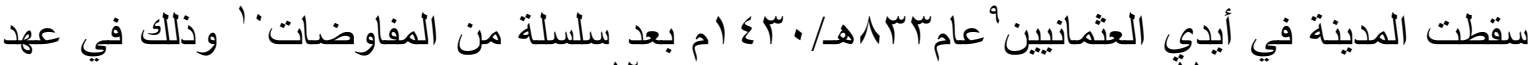

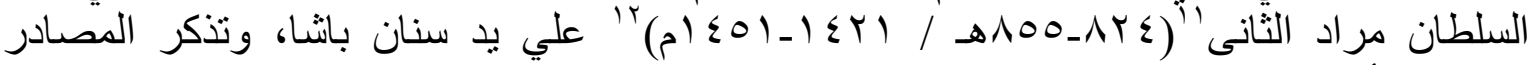

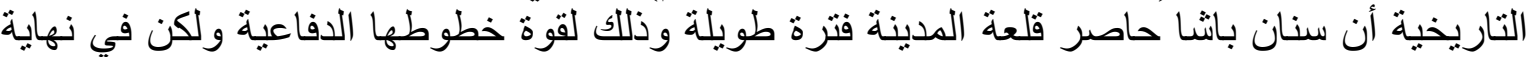

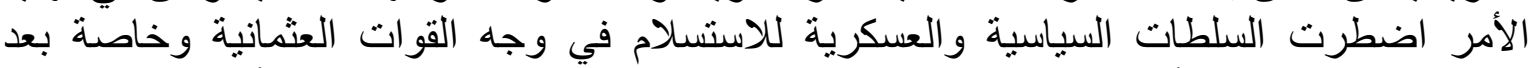
معرفته بالكارثة التي أطاحت بسالونيك في نفس العام،وقام العثمانيون بعمل عهر لأهل المدينة يحفظ

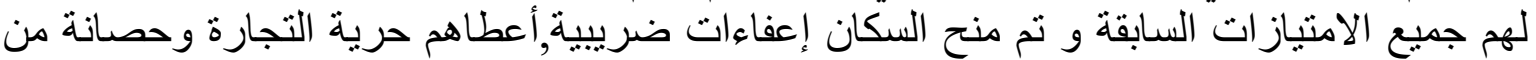
السجن والأسر،كما حافظ الأسقق على الحقوق الكنسية القديمة و القضاء، وتعهد العثمانيين بعدم

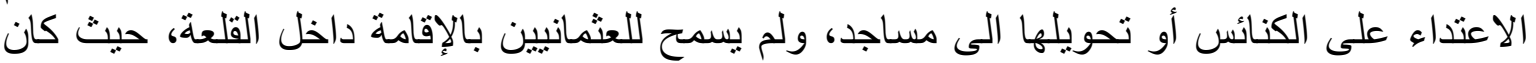

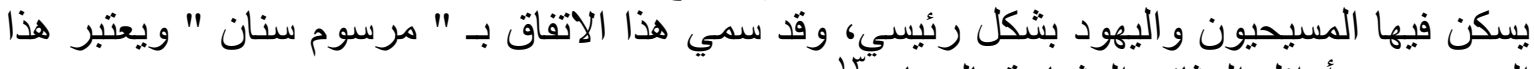
المرسوم من أو ائل الوثائق العثمانية باليونان. 
و خلال فترة القرن || اهـ/ ام ظهرت كثثير من حركات التمرد على الدولة العثمانية أهمها كانت عام

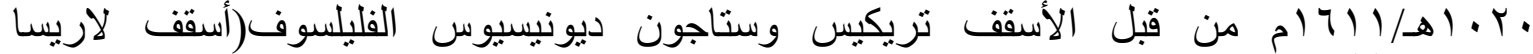
Larissa

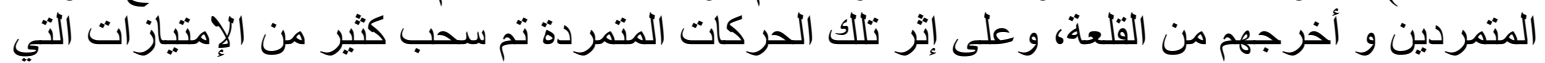

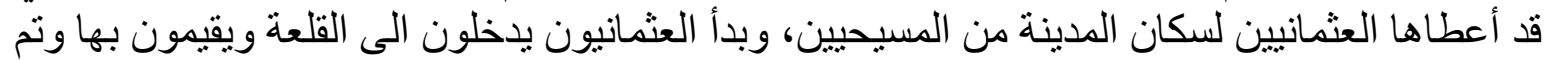

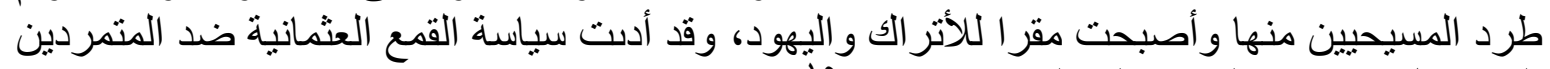

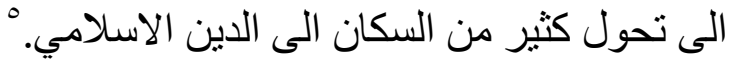

و ونذ أن استوطن العثمانيون قلعة المدينة شر عو ا في بناء المساجد و المؤسسات الدينية المختلفة لإقامة

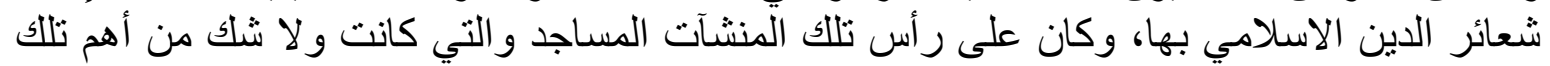
المؤسسات التى كان يحرص المسلمون بصفه عامة على إقامتها في المدن الجديدة التي يتم فتحها حيث تعد ر امز آ للدين الاسلامي. الني

\section{الار اسة الوصفية لمسجد والى باشيا}

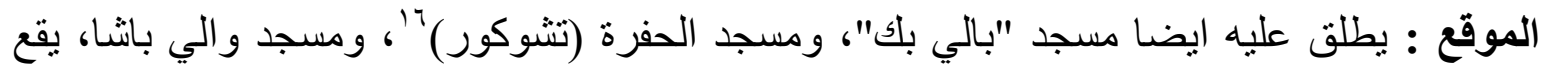

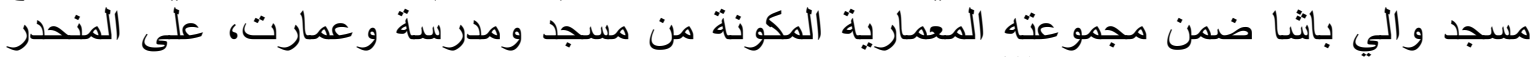

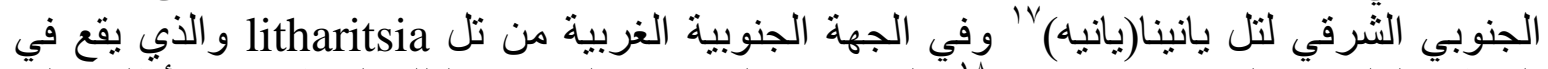

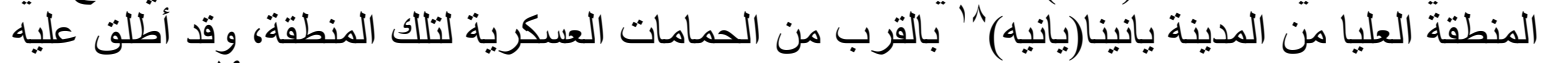

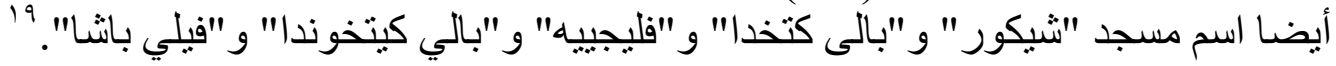

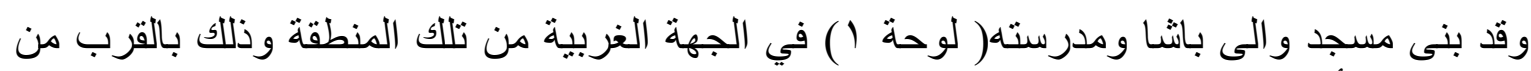

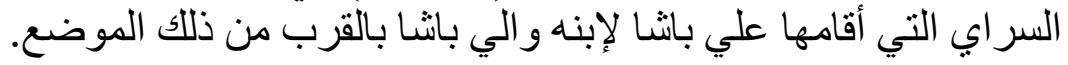

هذا المجمع يقع في وسط منطقة مفتوحة كبيرة، تشكلت من الحافة الجنوبية الثرقية للتل، المنطقة

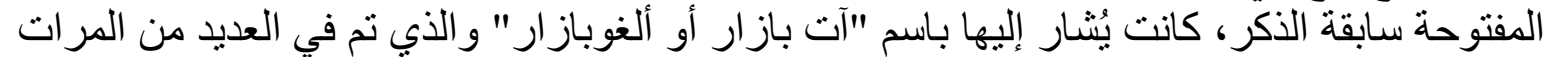

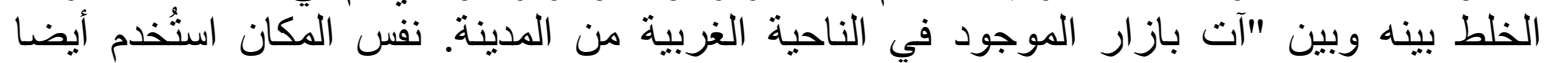

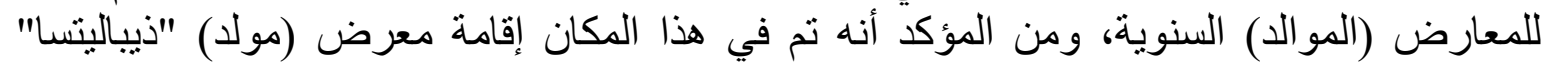

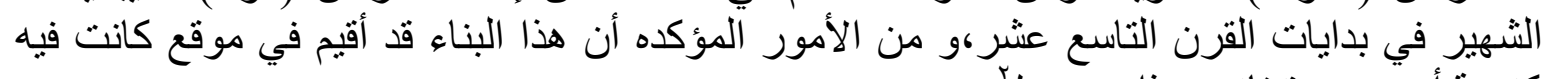

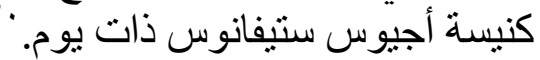

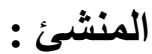

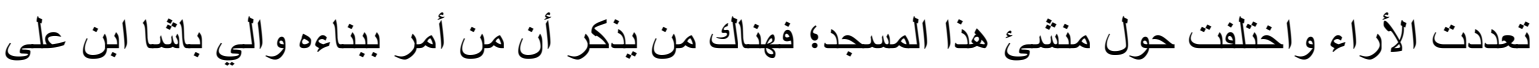

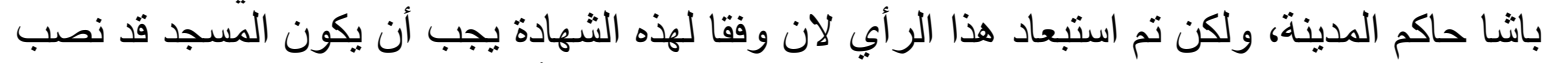

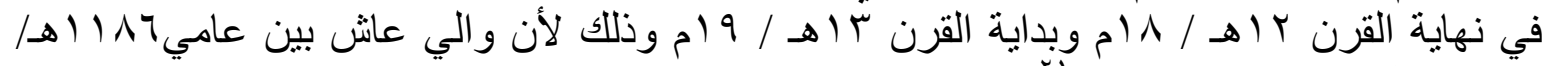

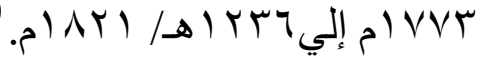

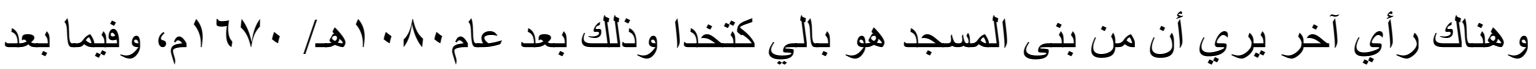

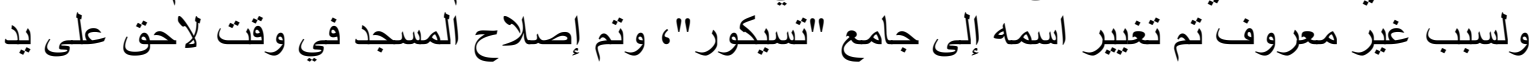

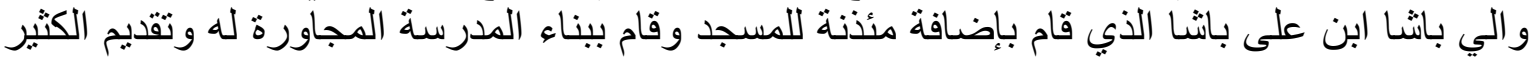

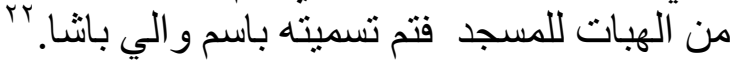


وفقا لبعض الاستشهادات التراثية (المنقولة شفهيا)، فإن جامع "الحفرة" - و الذي سُمي باسمه فيما بعد - بُني في مكان معبد القيس "ستيفانو" Agios Stephanos البيزنطي.

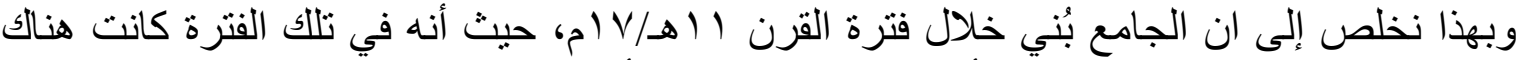

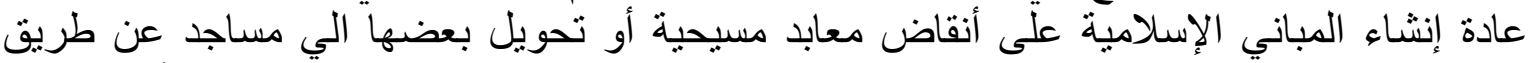

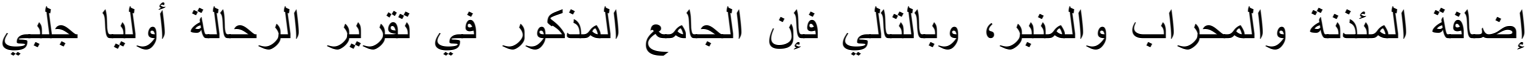

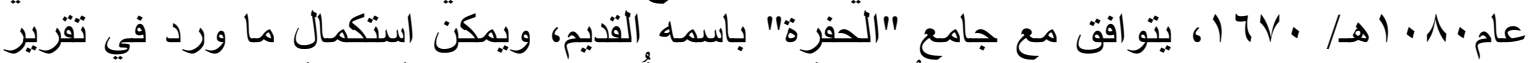

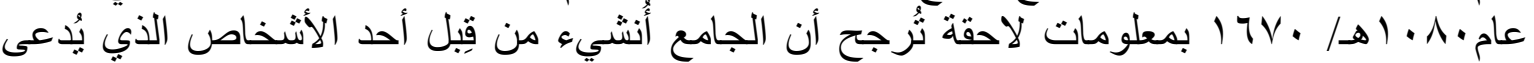

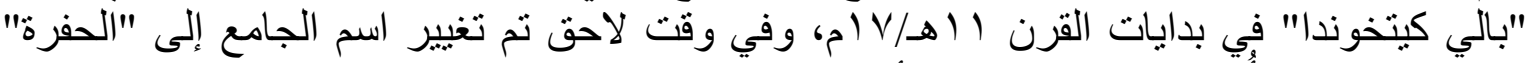

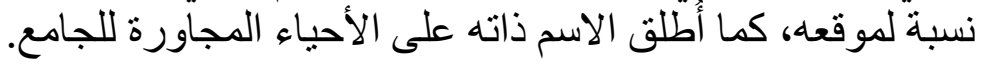

و في وقت لاحق تم إصلاح المبنى و إضافة مئذنة و تحويله من مسجد الى جامع و ذلك ألى على يد و الي

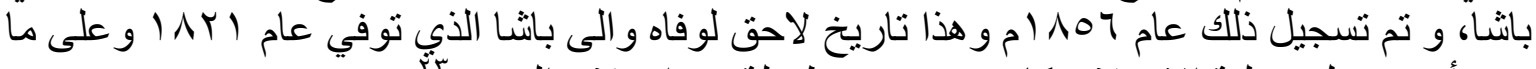

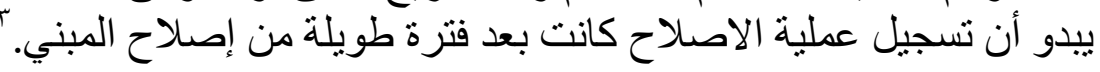

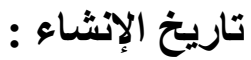

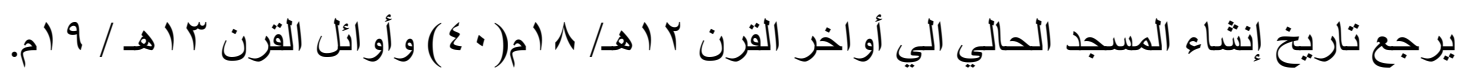

الوصف المعماري للمسجد :

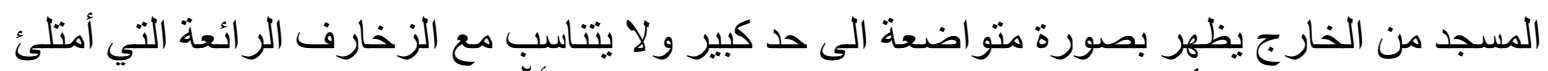

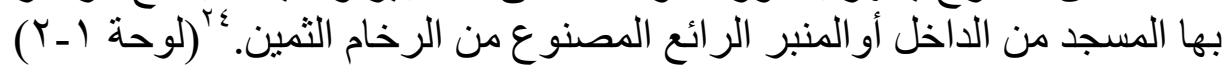

و المسجد في تخطيطه العام عبارة عن مساحة أبعادها7×هم؛ تنقسم الى مساحة مربعة مغطاه بقبة

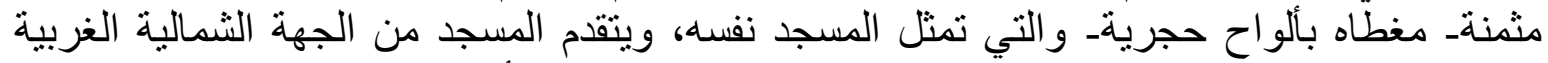

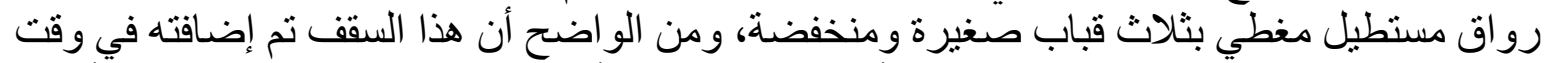

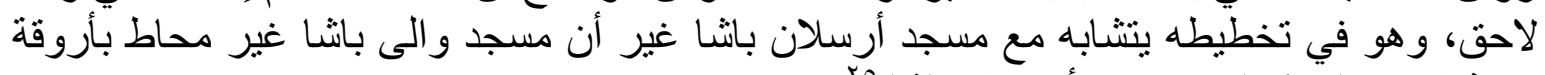

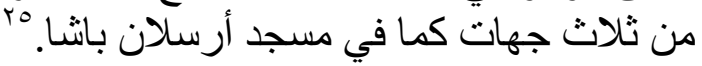

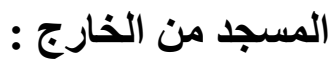

نلاحظ أن المسجد من الخارج عبارة عن جزئين متلاصقين مع بعضهما البعض، الجزء الأول الأل عبارة

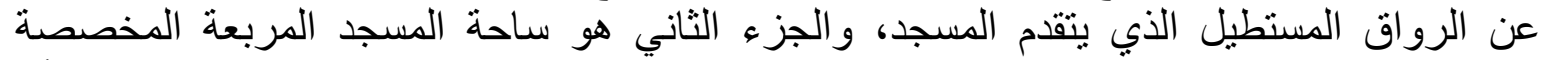

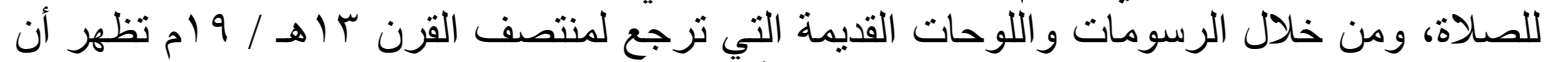

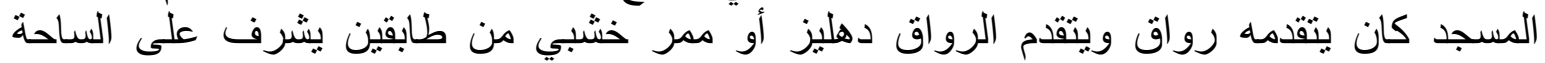

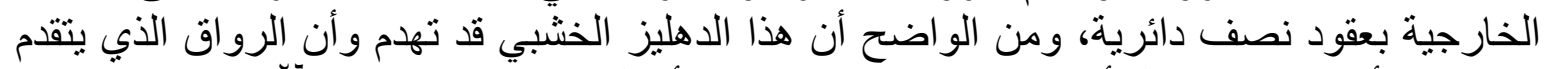

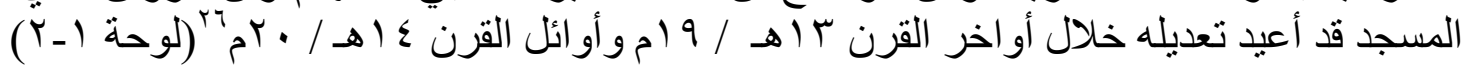

\section{الواجهة الشمالية الغربية :}

هي الو اجهة الرئيسية للمسجد(لوحة ب) والتي يوجد بها فتحة باب الدخول، وتعتبر واجهة الرواق الذي الذي

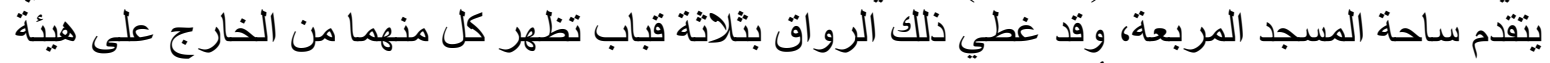
قبة مخروطية الثكل مغطاه بألو اح من الحجارة. 


$$
\text { وتنقسم هذه الو اجهة الى قسمين:- }
$$

القسم السفلي: يبدأ من الجهة الثمالية حيث يوجد فتحة شباك مسنطيلة مغشاه بالمصبعات المعدنية

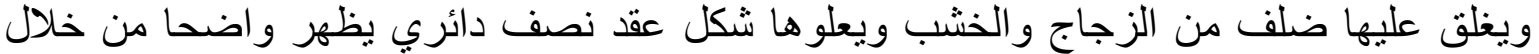

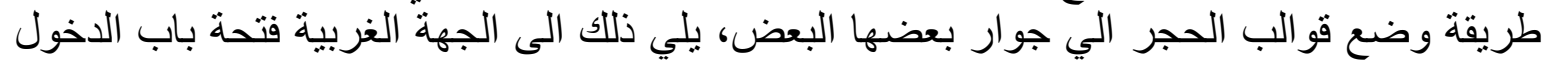

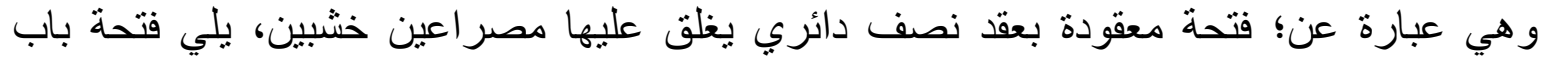

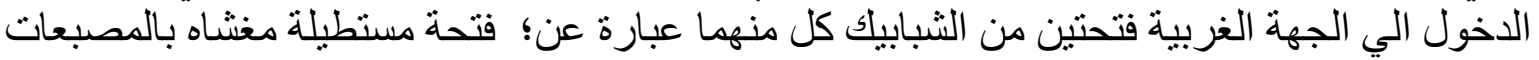

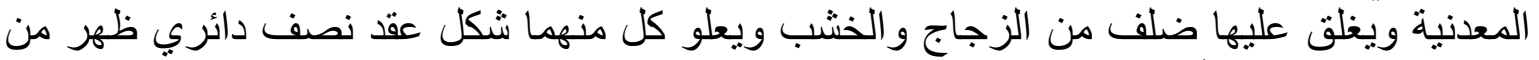

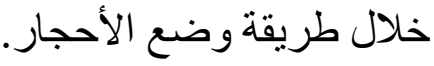

أما الطابق الثاني: فقد فتح به عدد ثلاث نو افذ، الوسطي عبارة عن فتحة معقودة بعقد نصف دائري

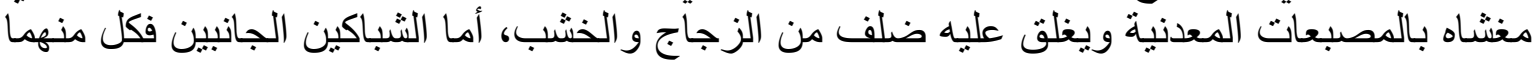

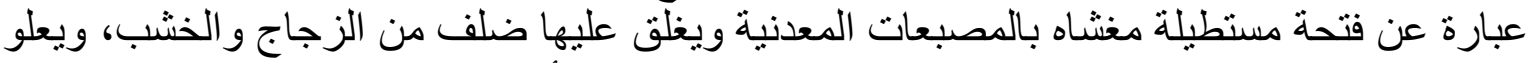
كل منهما شكل عقد نصف دائري ظهر من خلال طريقة وضع الأحجار.

ومن الجدير بالملاحظة أن النافتتين الجانبيتين العلويتين توجدا على نفس محور النافتتين الجانبيتن

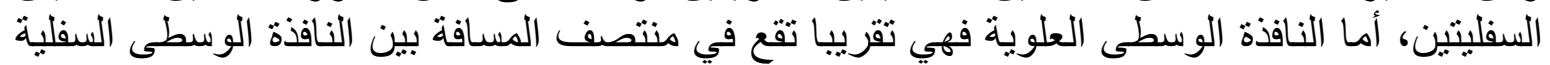

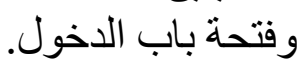

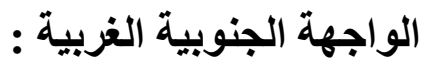

تضم هذه الواجهة كل من؛ الواجهة الجنوبية الغربية للرواق الذي ينقام المسجد، وكتلة المئذنة،

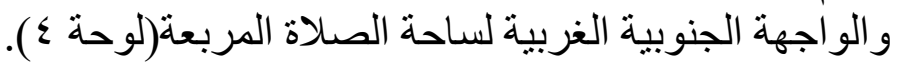

الو اجهة الجنوبية الغربية للرواق الذي يتقدم المسجد إنقسمت الى قسمين سفلي و علوي و هما متشابهان

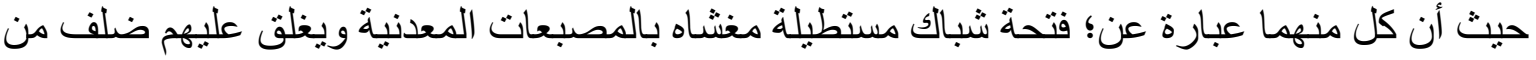

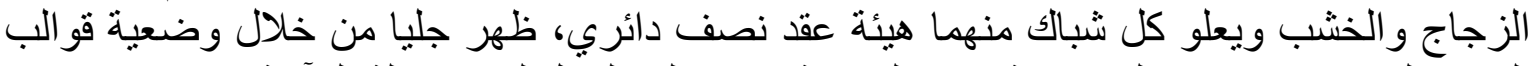

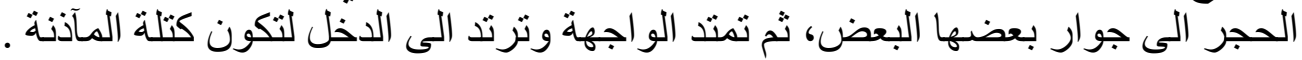

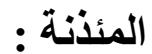

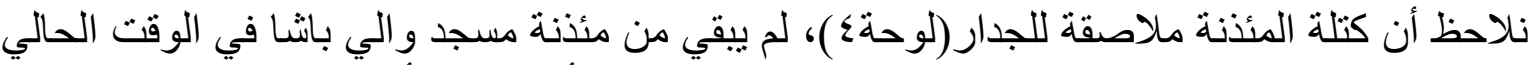

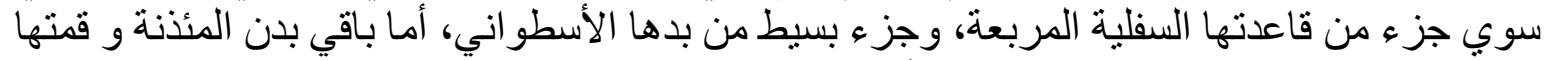

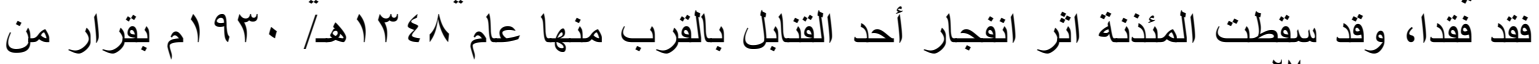

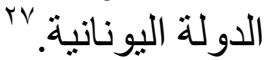

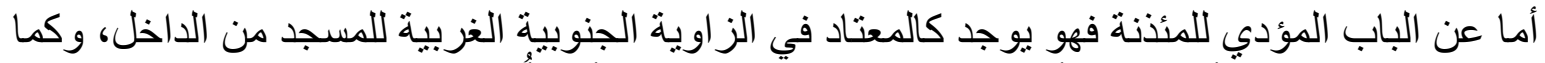

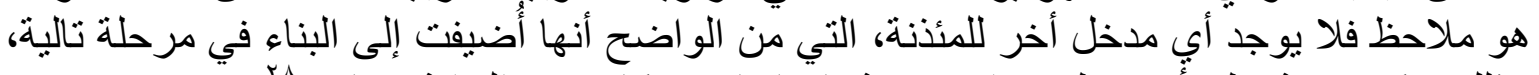

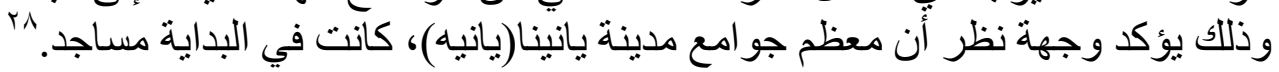

ترتد الواجهة مرة أخري بعد إنتهاء كتلة المئذنة وتمتد الى الجهة الجنوبية لتكون الجدار الجنوبي

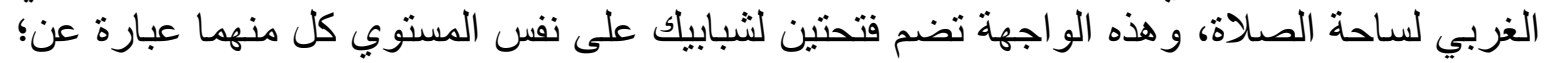

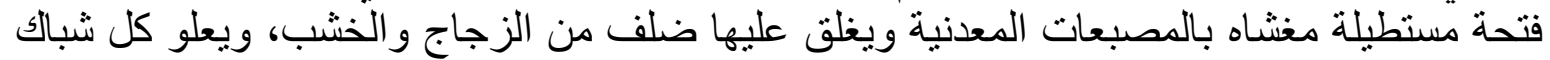
منهما هيئة عقد نصف دائري، ظهر جليا من خلال وضعية قو الب الحجر اللى جوار بعضها لئها البعض. 


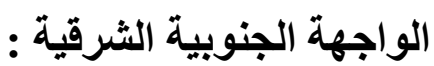

و هي الواجهة التي تضم جدار القبلة من الداخل(لوحة ه)، وقد فتح في هذه الواجهة شباكين على نفس ونس

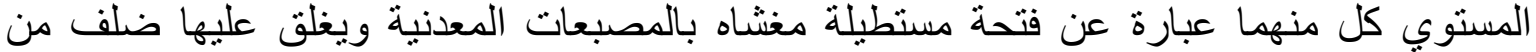

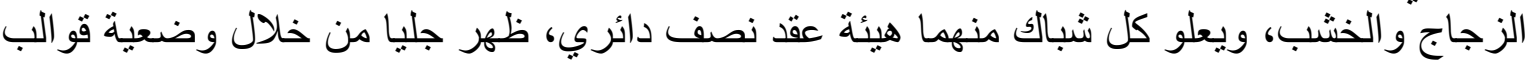

الحجر الى جوار بعضها البعض.

\section{الواجهة الشمالية الشرقية :}

و تتقسم هذه الواجهة الي قسمين(لوحة ب)؛ قسم يمثل الواجهة الثمالية الثرقية لمربع ساحة الصلاة،

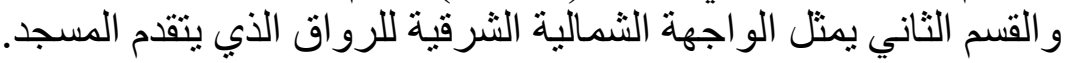

تبدأ الواجهة الثمالية الثرقية لساحة الصلاة من الزاوية الثرقية وتمتد نحو الناحية الثمالية وهي

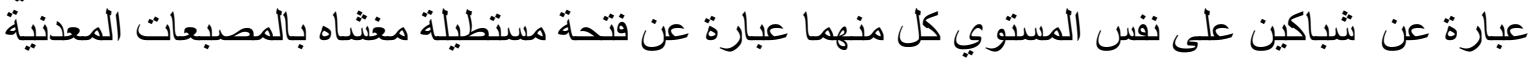

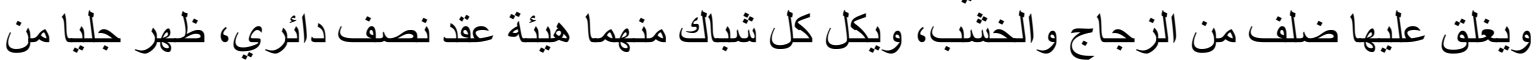

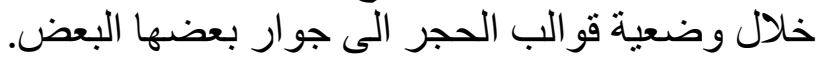

ثم تمتد الواجهة نحو الجهة الثمالية لتكون الواجهة الثمالية الثرقية لكتله الرواق الذي يتقدم المسجد و هذه الواجهة عبارة عن؛ قسمين سفلي و علوي وكل منهما عبارة عن؛ فتحة شبالك مستطيلة مغشاه

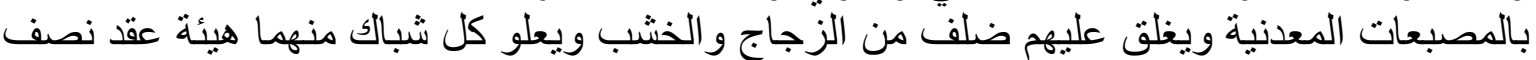
دائري، ظهر جليا من خلال وضعية قو الب الحجر الى جوار بعضها ونس البعض. ومن الملاحظ أن فتحات الثبابيك الموجودة في ساحة المسجد الداخلية أكبر من تلك النو افذ التي تم فتحها في الرواق الذي بتقدم المسجد. فئل

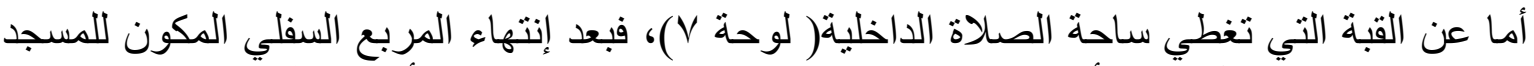
تظهر مناطق الأنتقال في الأركان حيث نلاحظ وجود زونة زواية مرتفعة في أركان المربع الفيع السفلي تنتهي

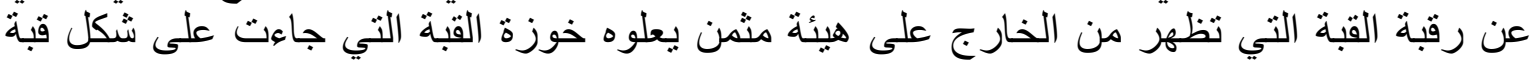
مخروطية الثكل مغطاه بألو اح حجرية.

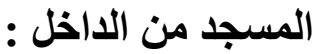

المسجد من الداخل حاليا في حالة سيئة لانه لم يتم الاعتناء به لفترة طويلة .

يلي فتحة باب الدخول رواق مستعرض مغطي بثناث قباب(لوحة م ) )، وفي صدر هذا الرواق يوجد فتحة باب الدخول لحجرة الصلاة وتحديدا في منتصف المسافة بين القبتين الثمالية و الوسطي، ودئ وهي

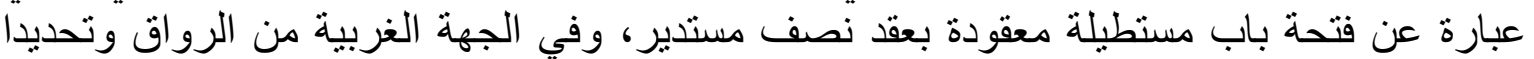

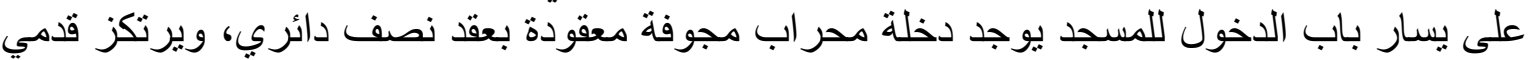

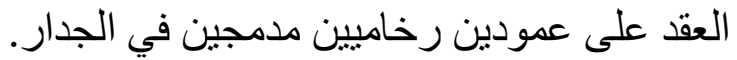

وفي كل من الزاوية الثمالية والزاوية الغربية من الرواق يوجد فتحة شباك مستطيلة تفتح على ساحة المسجد الداخلية.

وفي المستوي العلوي نلاحظو جود ثلاث فتحات كل منها عبارة عن فتحة مستطيلة معقودة بعقد نصف دائري. 


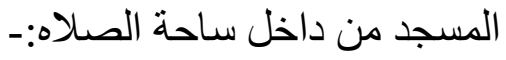

أرضية ساحة الصلاه الداخلية مدمرة بالكامل مليئة بالركام(لوحة 9 - • ( )

الجدار الجنوبي الشرقي ( جدار القبلة ) للمسجد من الداخل :

وهو الجدار الرئيسي لساحة الصلاة الداخلية، وقد فتح به شباكين كل منهما عبارة عن دخلة مستطيلة

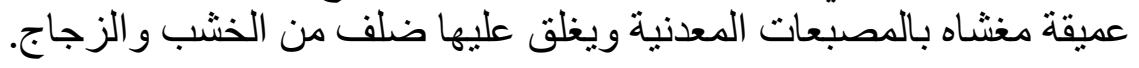

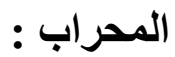

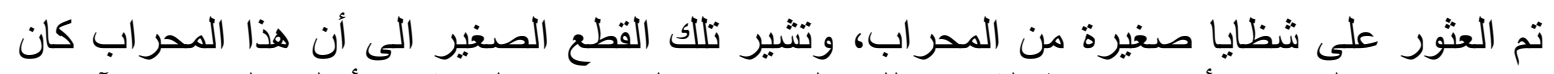

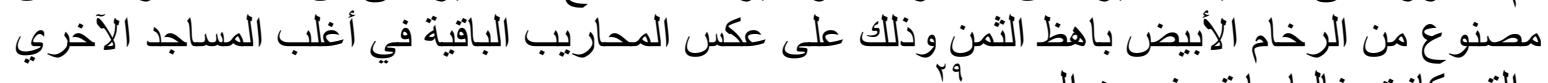

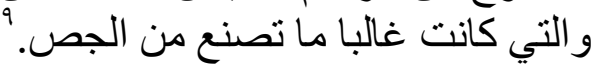

أما المحر اب حاليا فهو في حاله سيئة للغاية و متهدم بشكل كامل. الجدار الجنوبي الغربي للمسجد من الداخل :

فتح في هذا الجدار فتحتين للثبابيك على مستوي واحد كل منهما عبارة عن؛ دخلة مستطيلة عميقة

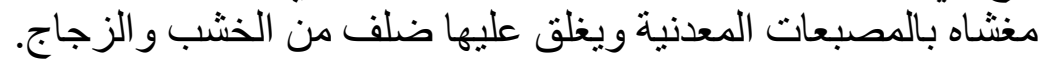

وفي الز اوية الغربية من هذا الجدار وتحديدا في مستوى مرتفع توجد فتحة مستطيلة معقودة بعقد نصف دائري، كانت تلك الفتحة قديما باب الوصنة الوصول للمئذنة.

\section{الجدار الشمالي الغربي للمسجد من الداخل :}

يوجد في هذا الجدار فتحة باب الدخول وهي عبارة عن؛ دخلة عميقة مستطيلة يغلق عليها مصر اعي باب من خثب.

\section{الجدار الشمالي الشرقي للمسجد من الداخل (لوحة م 1) :}

فتح في هذا الجدار فتحتين للثبابيك على مستوي واحد كل منهما عبارة عن؛ دخلة مستطيلة عميقة

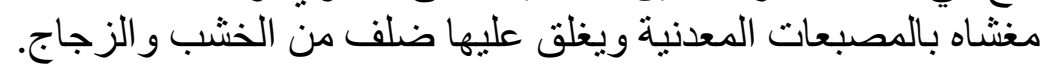

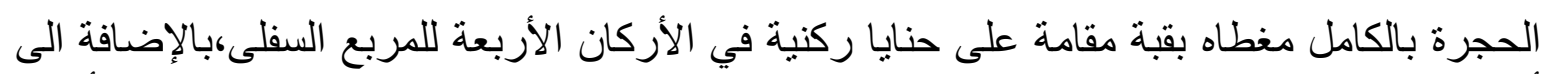

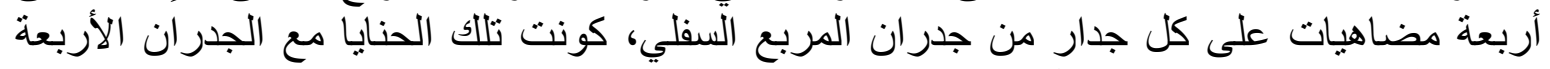

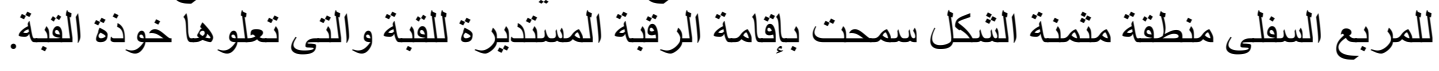

الاراسة التحليلة المقارنة:

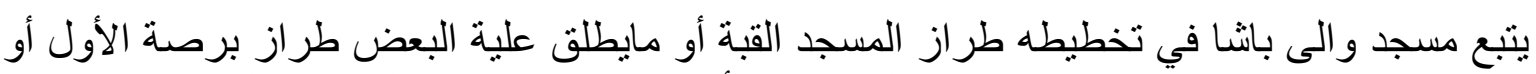

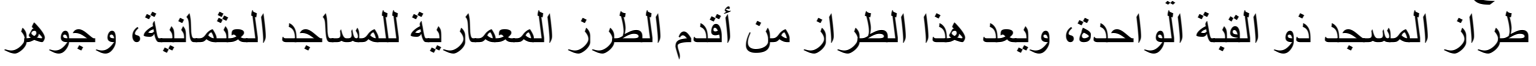

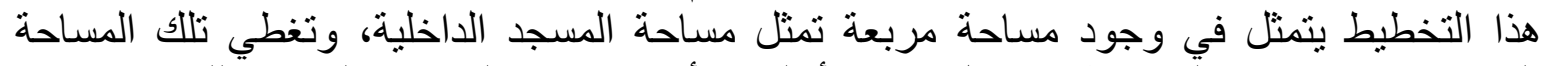
المربعة بقبة مقامة على منطقة انتقال، وفي أغلب الأحيان يتقدم المساحة المربعة للمسجد روبة رواق خارجي مغطي. 


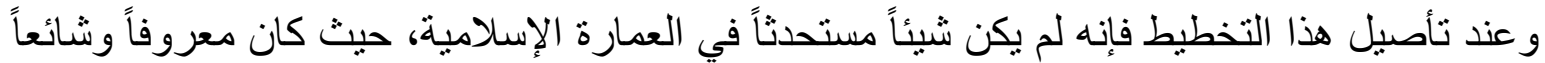

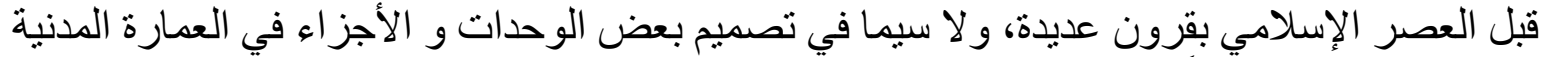

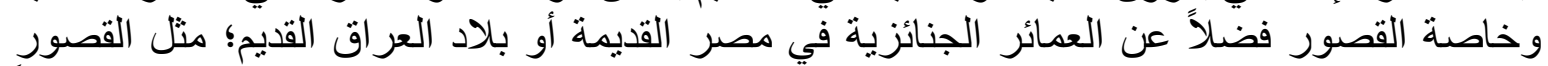

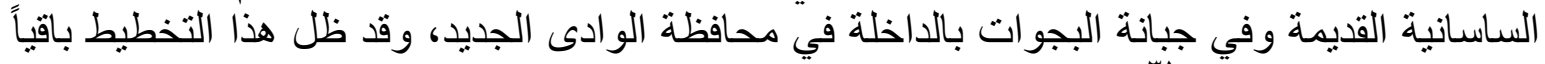

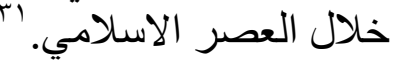

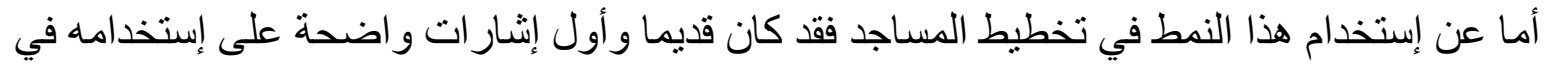

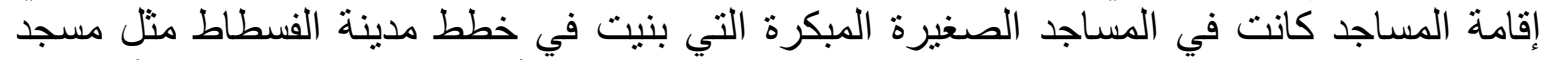

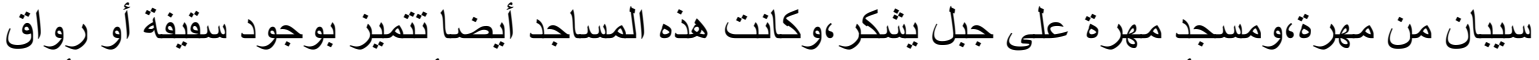

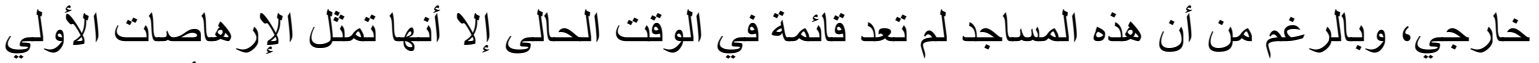

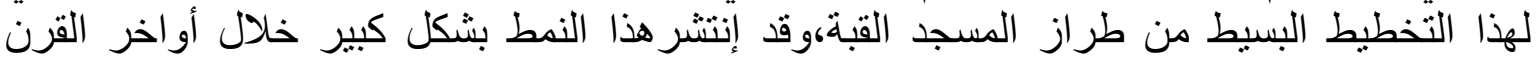

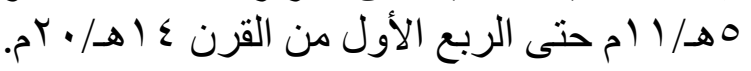

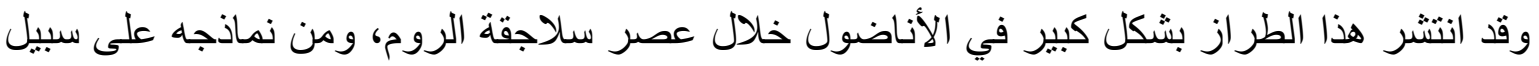

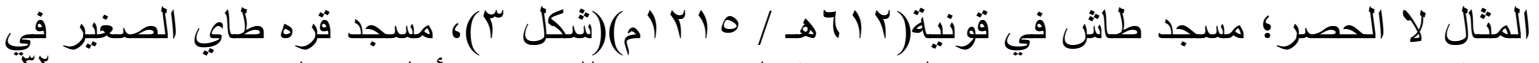

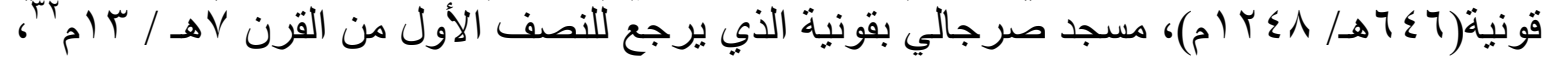

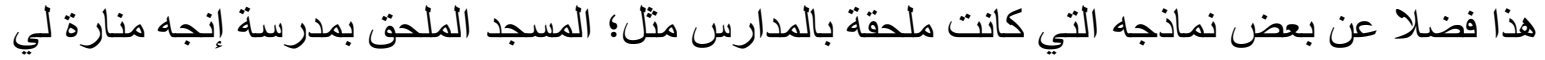

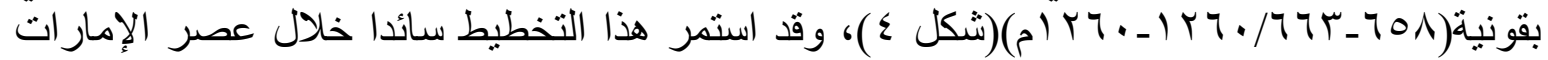

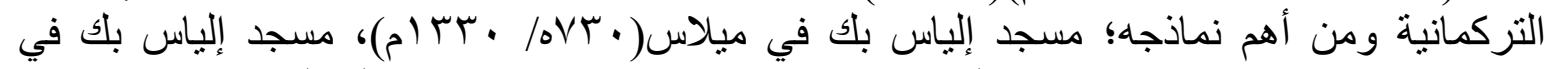

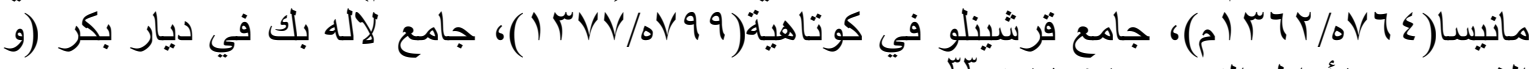

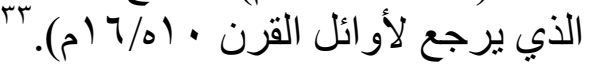

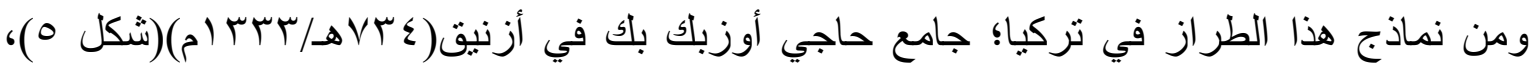

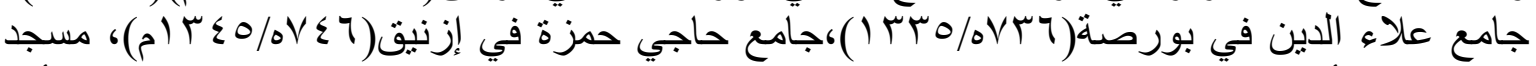

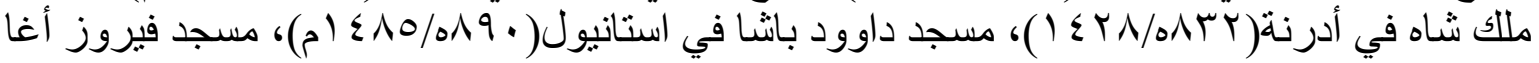

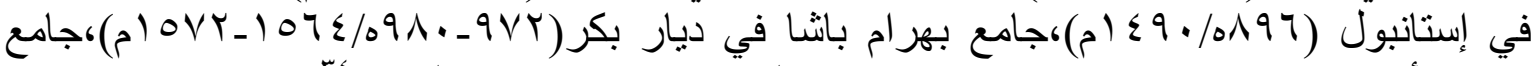

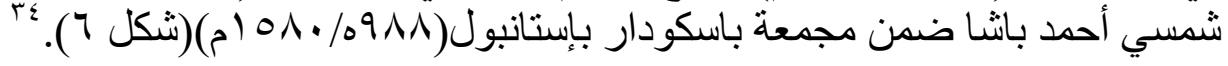

وأنتشر هذا النمط بشكل كبير في أرجاء الإمبراطوية العثمانية فنجد من نماذجانهاه في أوروبا

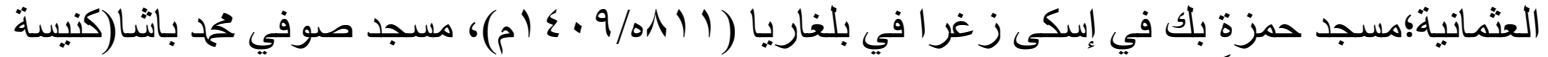

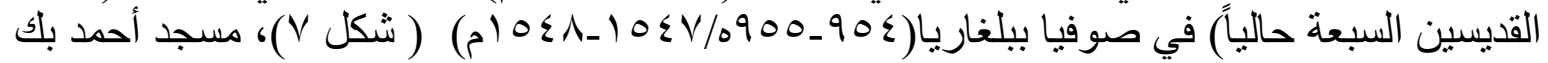

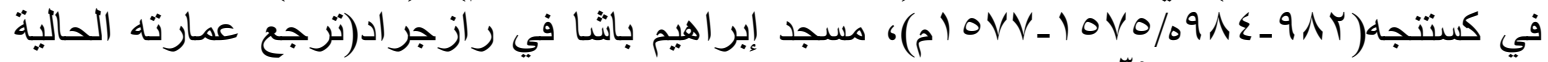

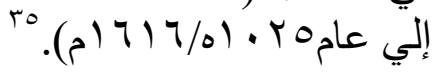

ومن نماذجه في المجر؛ مسجد غازي قاسم بانشا في Pesc)

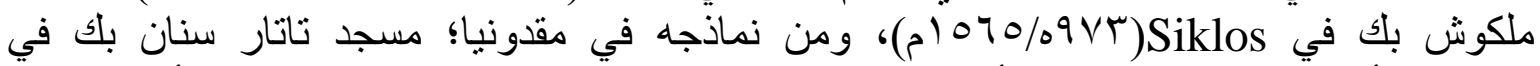

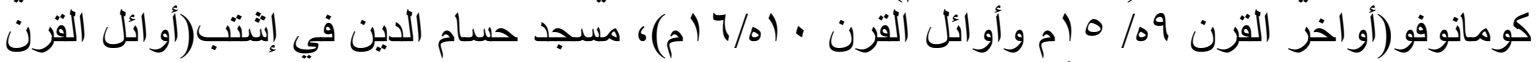

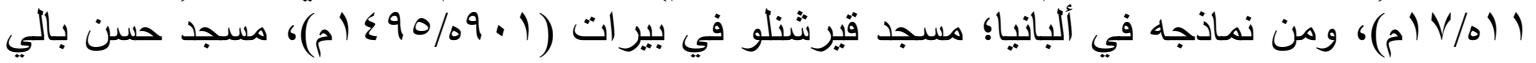

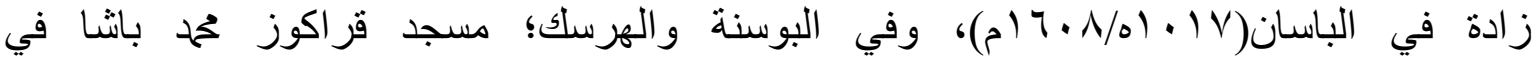

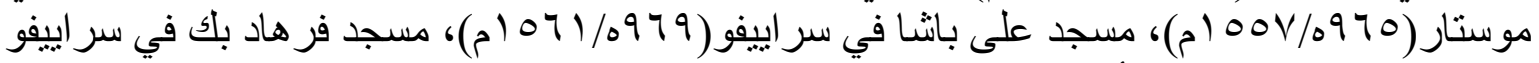

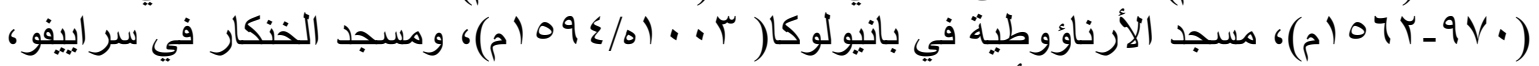

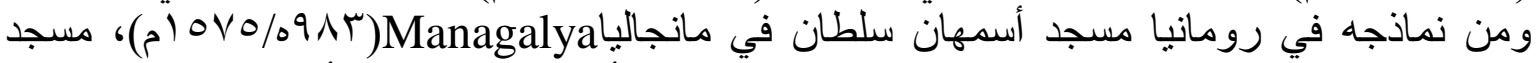

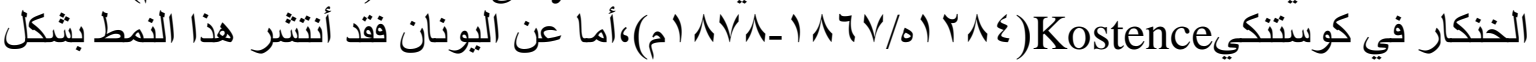




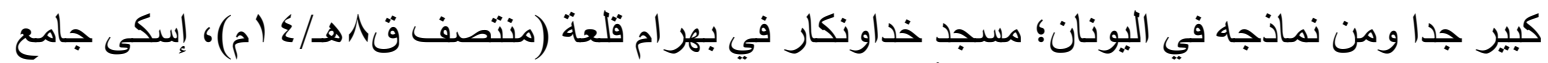

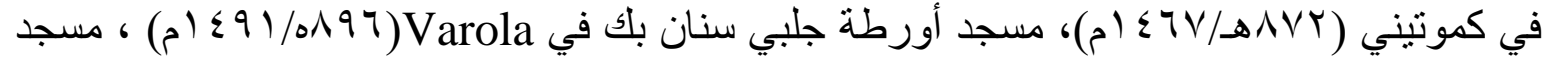

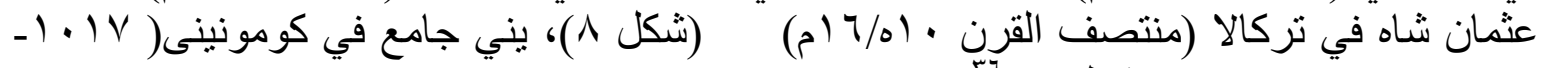

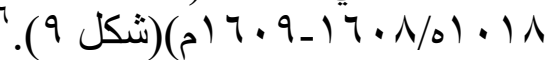

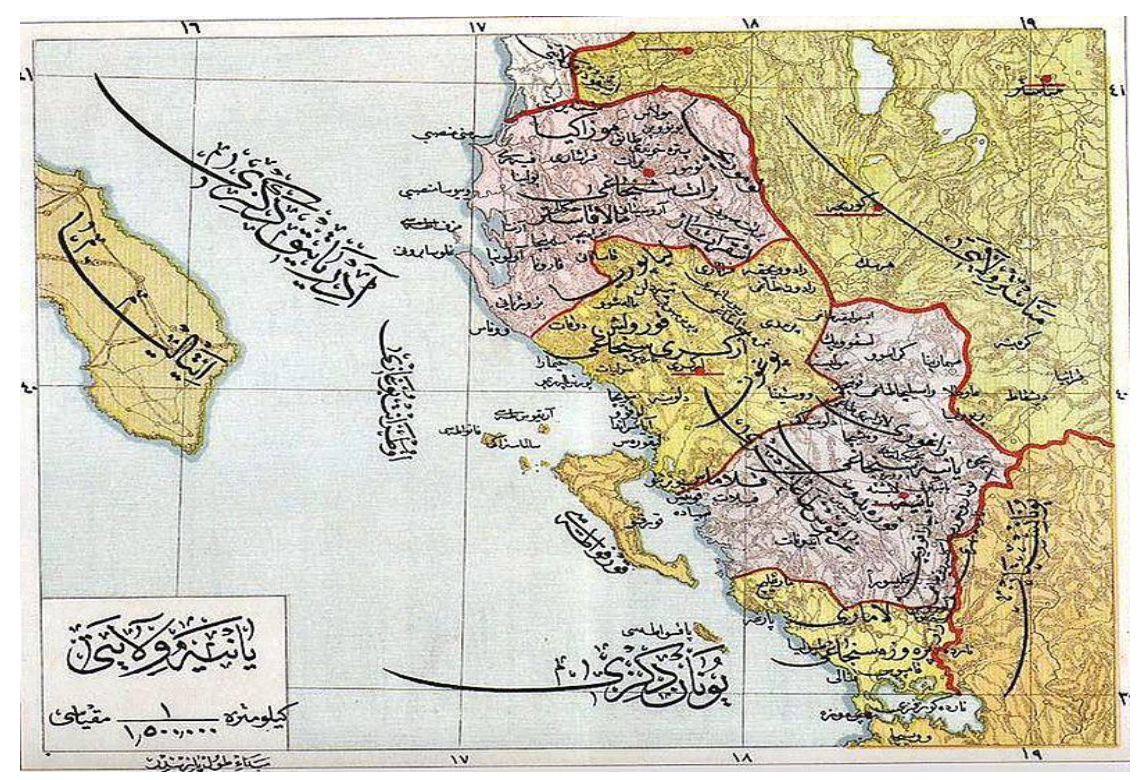

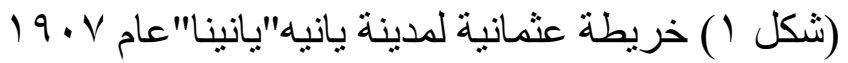

https://www.wikiwand.com/en/Sanjak_of_Preveza

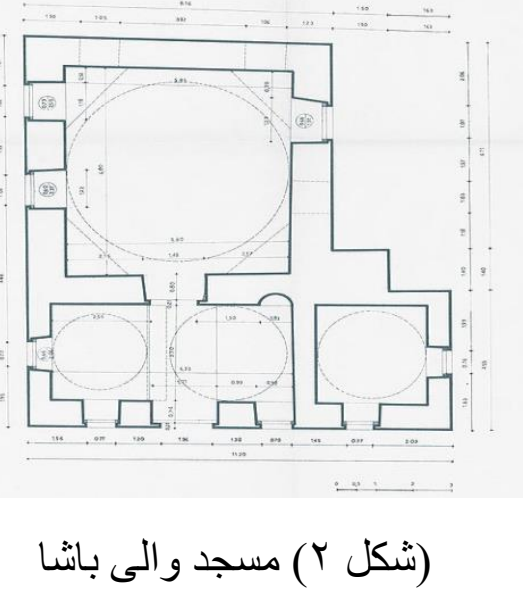

http://earthlab.uoi.gr/escutis/fend_object_details.php?objitem=89 


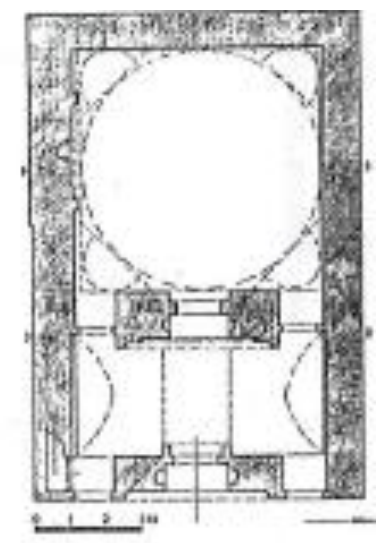

(شكلץ) مسقط أفقي لمسجد طاش في قونية

أصلان أبا، فنون الترك،ص إ)

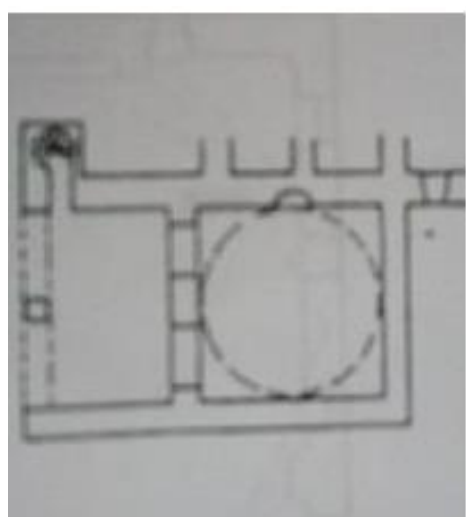

(شكل § ) مسقط أفقي للمسجد الملحق بمدرسة أنجة منار لي بقونية

الحداد، طر از المسجد القبة، شكلع إ

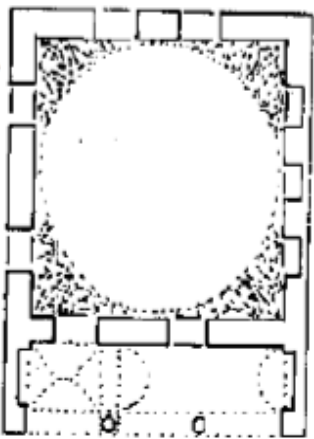

$$
\text { (شكل 0) مسجد حاجي أوزبك في ازنيق }
$$

Suslu, O, Facades Views of the Turkish Anatolian Architecture, Archeologie Islamique, vol4, Paris, 1994, F:7 


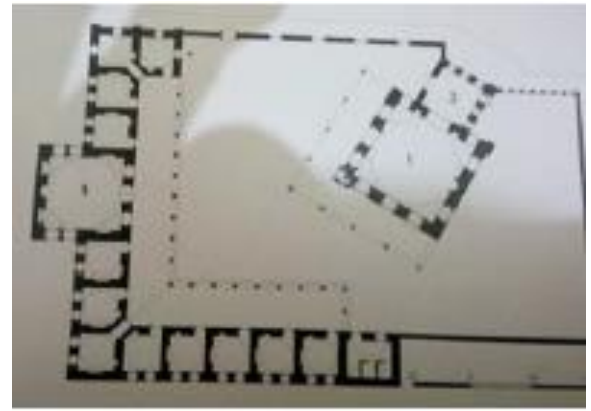

(شكل T) جامع شمسي أحمد باشا

Kuran, the mosque in Early ottoman Architecture, 1968. P336
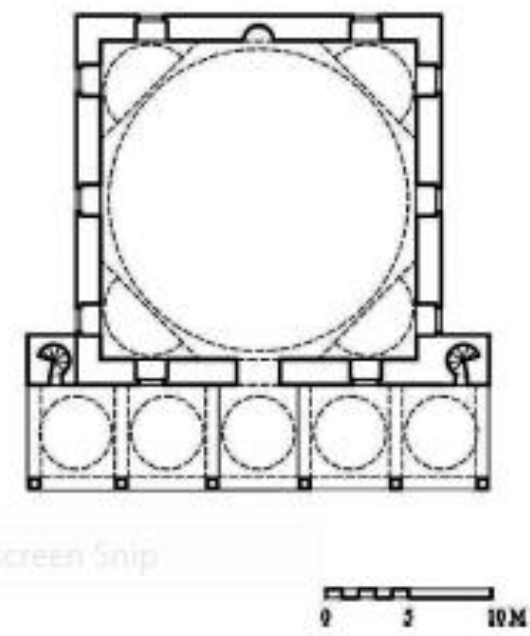

(شكل V) مسقط أفقي لمسجد صوفي حمد باثا في صوفيا ببلغاريا

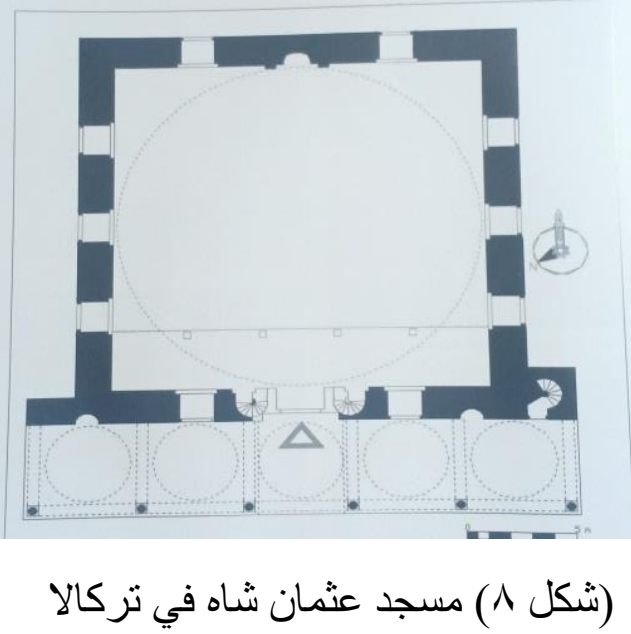

Ameen,Islamic Architecture, p172 


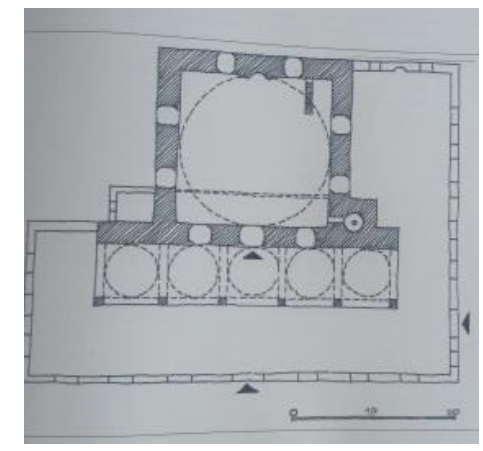

$$
\text { (شكل 9) ينى جامع في كو ميتينى }
$$

Ameen,Islamic Architecture, p155

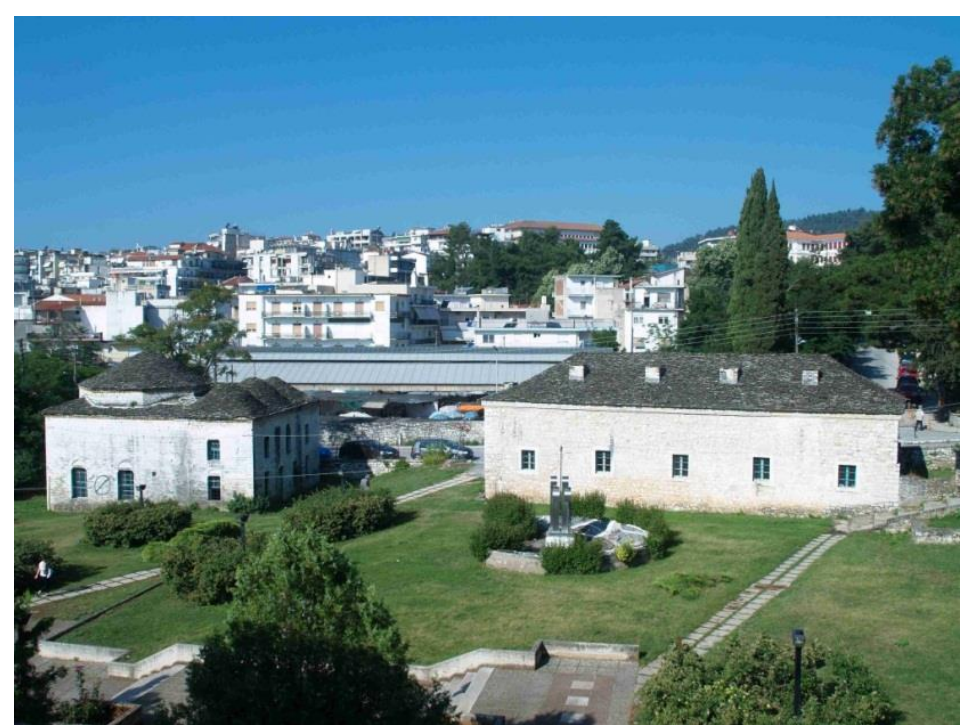

$$
\text { ( لوحة ( ) مسجد و مدرسة و الى باثا (بمعرفة الباحثة ) }
$$

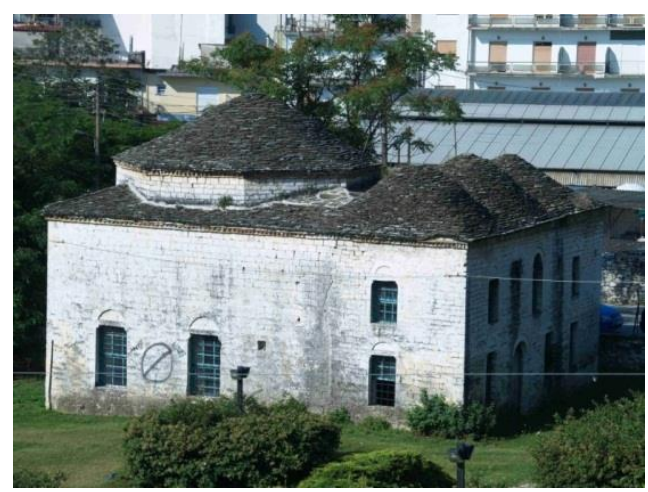

(لوحة ץ) مسجد و الى باثنا (بمعرفة الباحثة ) 


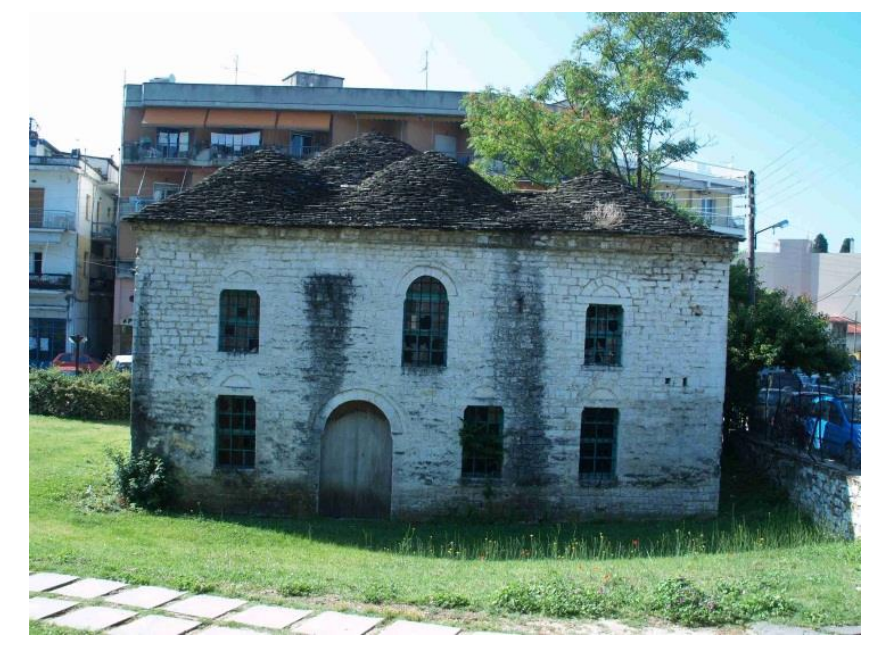

(لوحة ب) الو اجهة الثمالية الغربية لمسجد و الى باثـا (بمعرفة الباحثة )

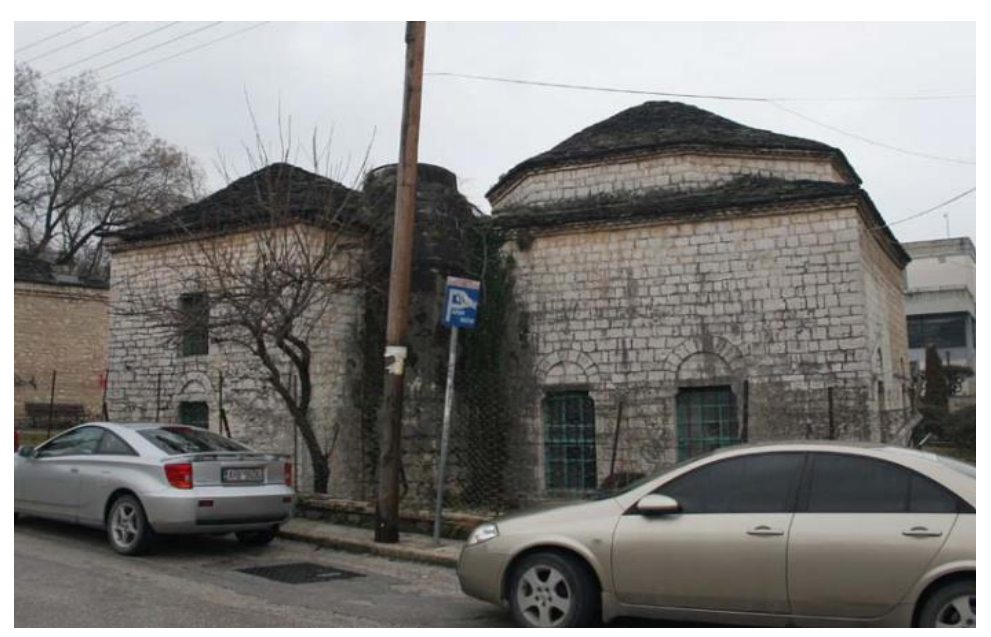

$$
\text { (لوحة ؟) الو اجهة الجنوبية الغربية لمسجد والى باثا }
$$

ÖZTUĞ, YANYA MERKEZ OSMANLI MIMARİSI

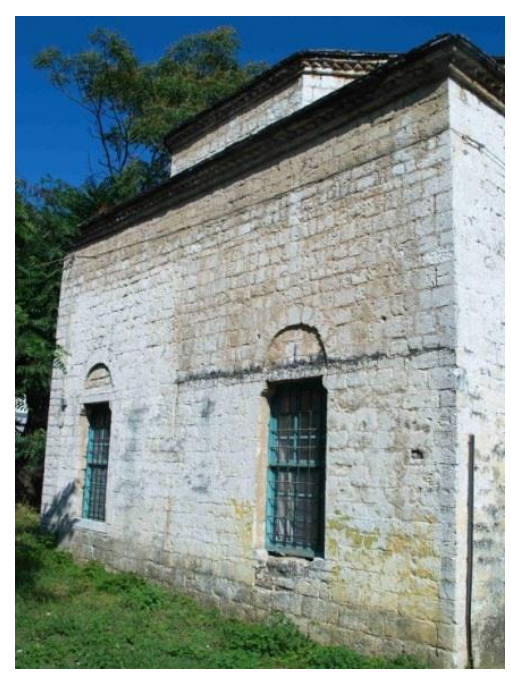

(لوحة ه) الو اجهة الجنوبية الثرقية لمسجد والى باثشا (بمعرفة الباحثة ) 


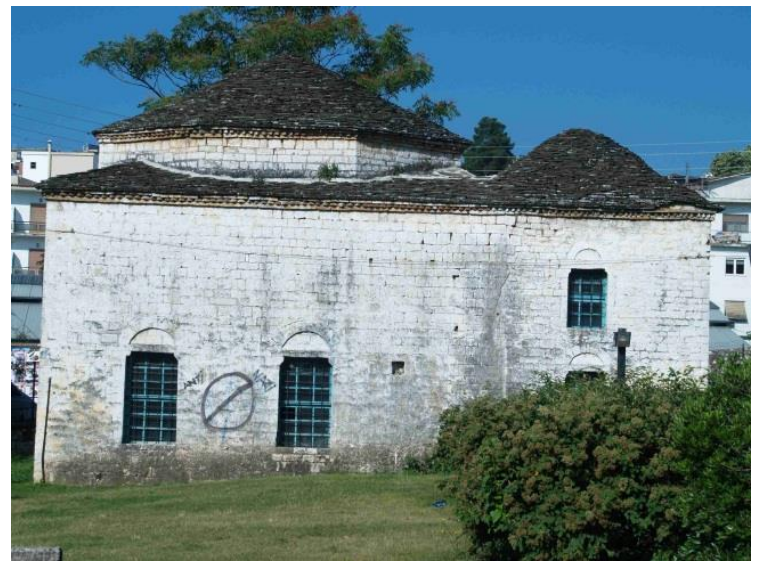

( لوحة 7) الو اجهةالثمالية الثرقية لمسجد و الى باثـا (بمعرفة الباحثة

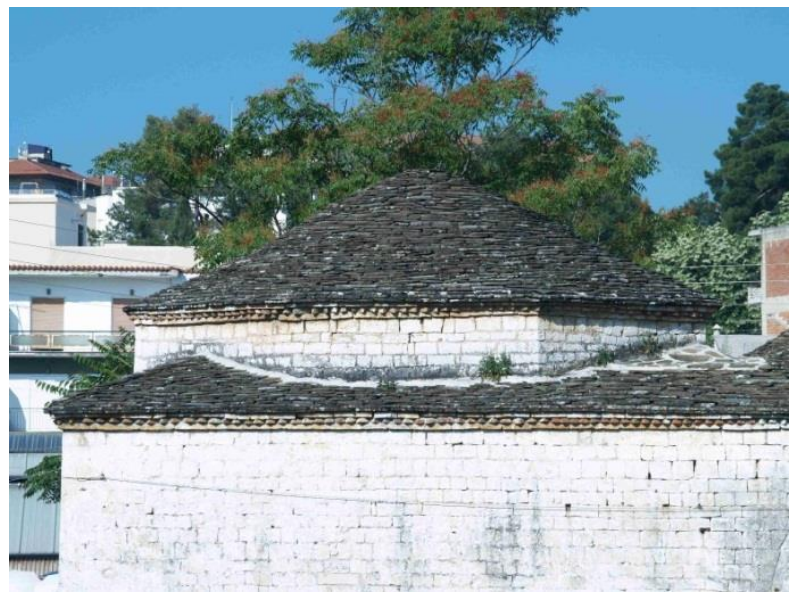

( لوحة V) القبة الى تغطى مسجد و الى باشـا (بمعرفة الباحثة )

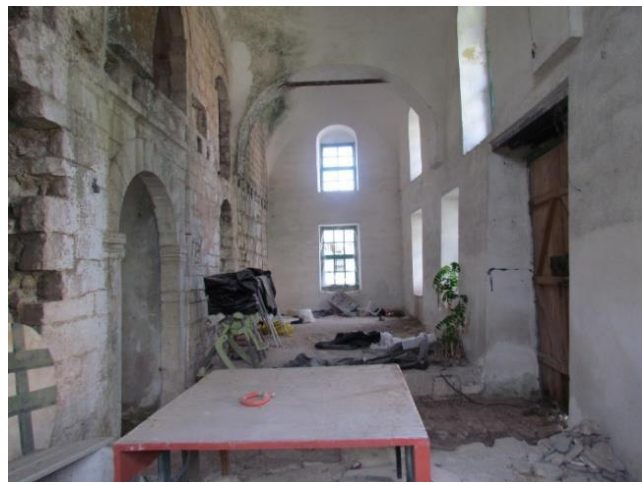

(لوحة م ) الرواق المستعرض الذي يتقدم حجرة الصلاة في مسجد والى باشـا

ÖZTUĞ, YANYA MERKEZ OSMANLI MIMARISİ, 


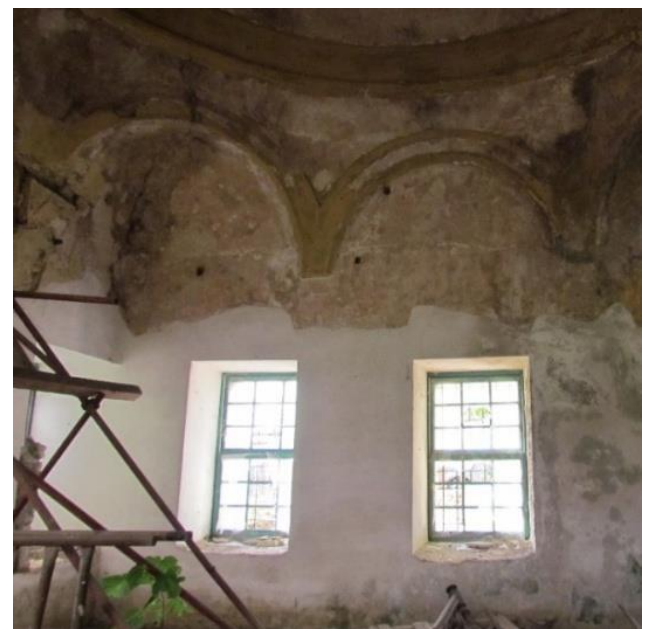

( لوحة 9) حجرة الصلاة في مسجد و الى بانشا

ÖZTUĞ, YANYA MERKEZ OSMANLI MIMARİSI,

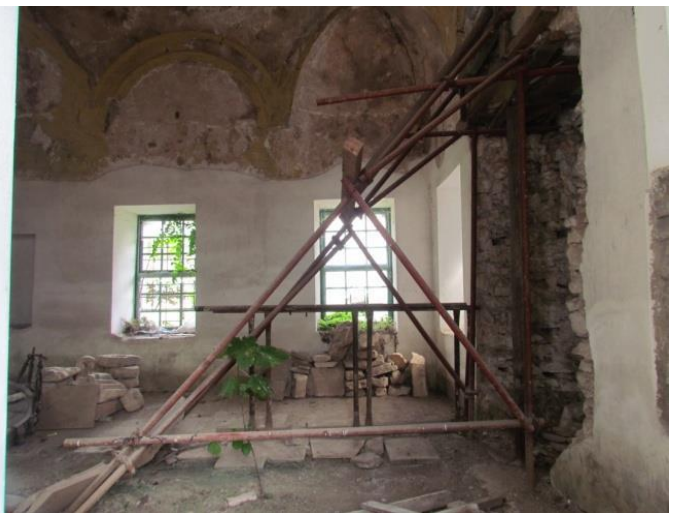

( لوحة 1 ) الجدار الثمالى الثرقي لمسجد والى باثشا من الداخل ،اعمال ترميم الدحر اب

ÖZTUĞ, YANYA MERKEZ OSMANLI MIMARİSI, 


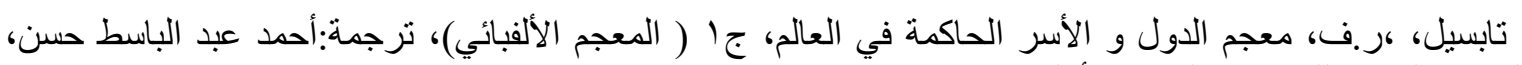

https://www.britannica.com/place/Epirus

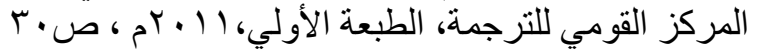

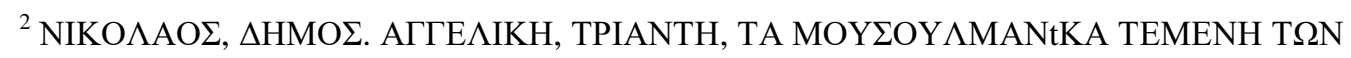

I $\Omega A N N I N \Omega N, \Sigma X O \Lambda H$ TEXNO $\Lambda O Г I K \Omega N$ ЕФАРМОГ $\Omega N$ TMHMA ПO $\Lambda$ ITIK $\Omega N \Delta O M I K \Omega N$ ЕРГ $\Omega N$,

IANOYPIO $\Sigma 2003, \sigma \varepsilon \lambda 5$

${ }^{3}$ ISLÂM ANSIKLOPEDISI , TÜRKIYE DIYANET VAKFI , CILT 43, Istanbul 1996,ss317-321

؛ دائرة المعارف الإسلامية ، إعداد و تحرير إبراهيم زكي خورشيد ـ أحمد الشنتناوي ـ عبد الحميد يونس ، المجلد

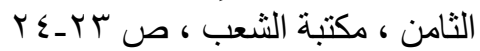

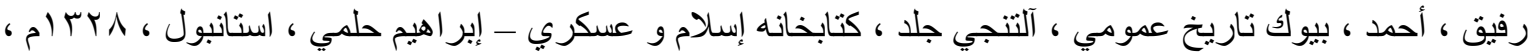

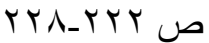

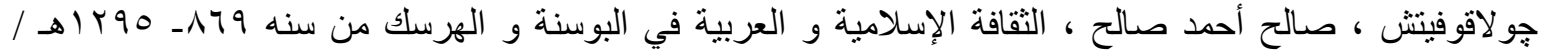

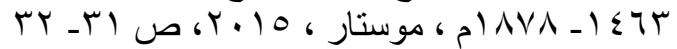

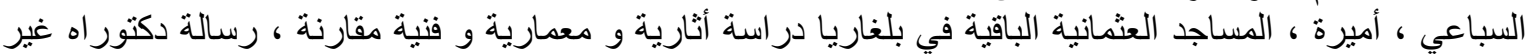

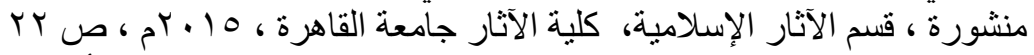

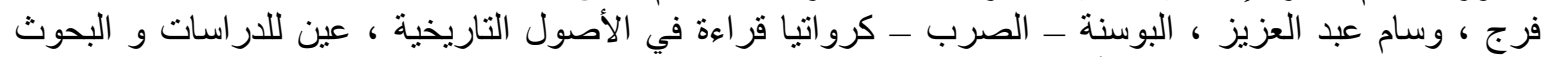

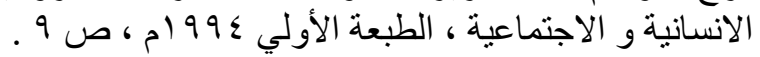

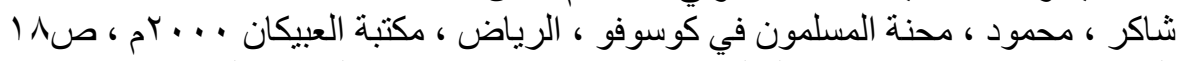

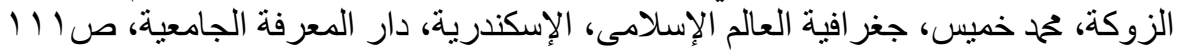

• صائب، على ،الجغر افية المفصلة لممالك الدولة العثمانية، ترجمة :جمعة بن أحمد أبو أحمد الأنطاكي، القسطنطينية

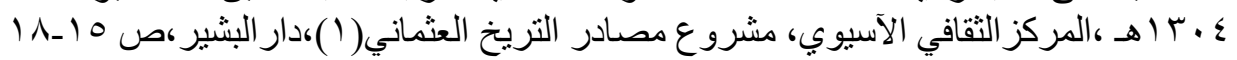

${ }^{6}$ The Encyclopaedia of Islam,New Edition, Vol XI,Brill Leiden 2002,p282

${ }^{7}$ Leak,Willian Martin, Travels in Northern Greece, J.Rodwell,1835,p405

${ }^{8}$ Spanou,Sofia Maria,Worled Heritage List:The Castle of Ioannina, Master of Art (MA)in Art Low and

Economy,International Hellenic University, Thessaloniki-Greece,January 2016,p19 9 اللمزيد من التفاصيل أنظر :

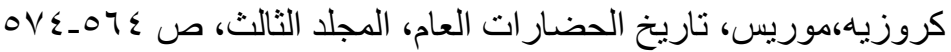

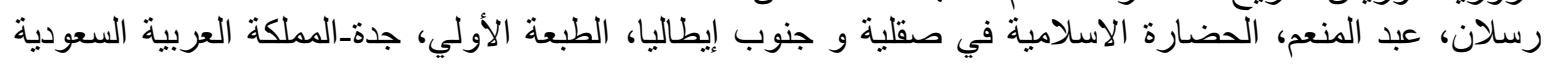
(1910.

العبادى، أحمد مختار - سالم،السيد عبد العزيز، تاريخ البحرية الاسلامية في حوض البحر الأبيض المتوسط، مؤسسة شباب الجامعة.

${ }^{10}$ NURJA, ERMAL, YANYA VILAYETI AMED-REFT DEFTERLERINE GÖRE YANYA'DA DINI KURUMLAR, YAPILAR VE DINII HAYAT, 5

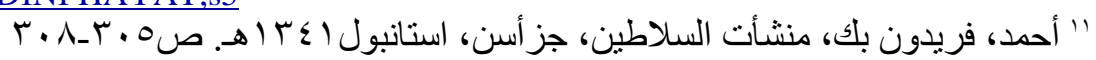

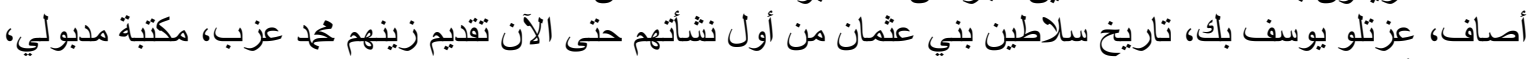

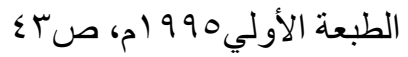

${ }^{12}$ KILIC ,Ayșegül ,Yanya'da İlk Osmanli Hâkımıyet Dönemı ve XIV.Yüzyila Aıt Unutulmuș Bır Zâviye,Balkan Araștirma Enstitüsü Dergisi,Cilt 5, Say1 1, Temmuz 2016 ,s148 ${ }^{13}$ Ameen,Ahmed, OTTOMAN USE OF EXISTING PUBLIC BUILDINGS IN FORMER BYZANTINE TOWNS: GREECE AS A CASE STUDY, 15th International Congress of Turkish Art, Naples, Università di Napoli "L'Orientale" 16-18 September 2015, Ankara 2018,p95

${ }^{14}$ ÖZTUĞ, YANYA MERKEZ OSMANLI MIMARISI, YÜKSEK LISANS TEZI SANAT TARIHII ANA BíLIM DALI, ANKARA HACI BAYRAM VELİ ÜNIVERSITTESİ LISANSÜSTÜ EĞITTIM ENSTITÜSÜ, EYLÜL 2019, ,s11

$\frac{15}{15}$ Doempke,Stephan,Coca,Anduela Lulo,Petrela,Sadl, Four Historic Cities In The Western Balkans, Tirana $\underline{2012, p 78}$ 


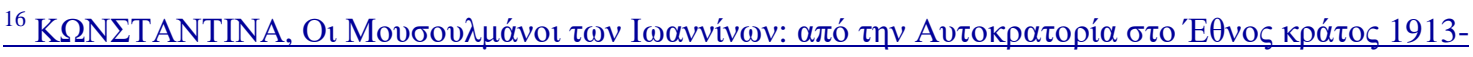

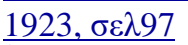

${ }^{17}$ Doempke,Stephan,Coca,Anduela Lulo,Petrela,Sadl, Four Historic Cities In The Western Balkans, Tirana 2012

${ }^{18}$ Ottoman Architecture IN Greece, Hellenic Ministry of Culture - Directorate of Byzantine and Post -

Byzantine Antiquities ,p174

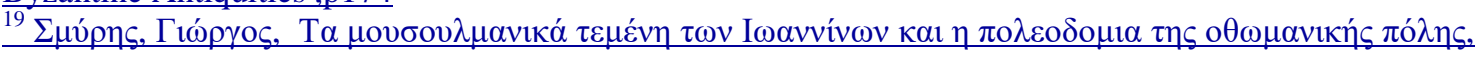

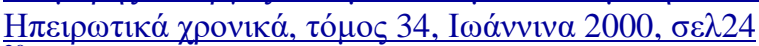

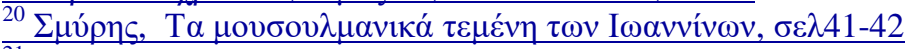

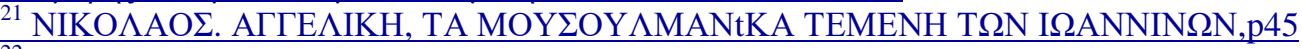

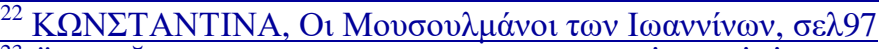

${ }^{23}$ ÖZTUĞ, YANYA MERKEZ OSMANLI MIMARİSI,s89

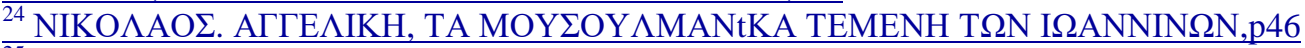

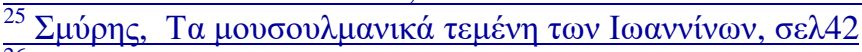

${ }^{26}$ Neumeier, The Architectural Transformation Of The Ottoman Provinces Under Tepedelenli Ali Pasha, 1788-1822,p177

27 ÖZTUĞ, YANYA MERKEZ OSMANLI MIMARİSİ,s84

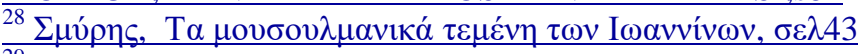

29 NIKO $\Lambda$ AO $\Sigma$. АГГE $\Lambda$ IKH, TA MOY $2 O Y \Lambda$ MANtKA TEMENH T $\Omega N$ I $\Omega A N N I N \Omega N, p 46$

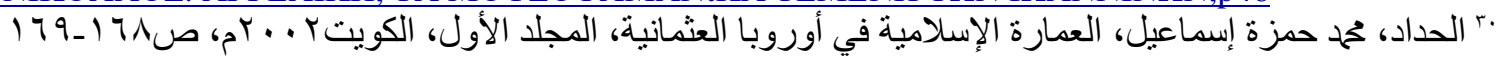

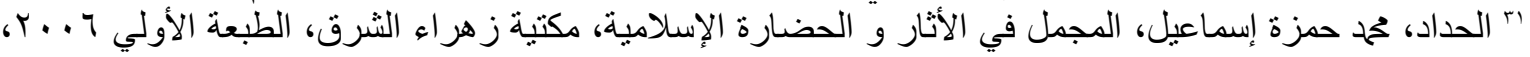

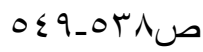

سيد، جمال صفوت، العمائر الدنينة في غرب اه الأناضول إبان عهد الإمارات (البكوات) دراسة أثرية معمارية فنية،

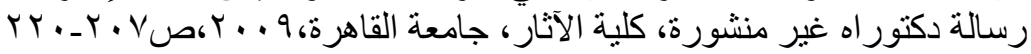

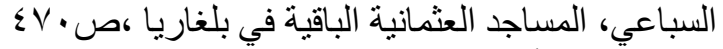

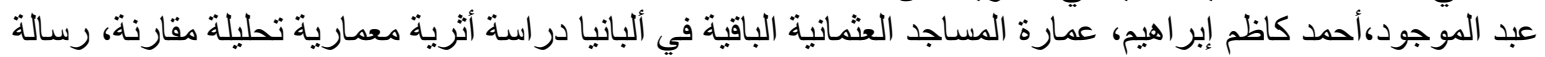

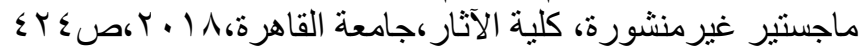

rr أصلان ابا،أوقطاي، فنون الترك و عمائر هم، ترجمة أحمد حمد عيسي، مركز الأبحاث والفنون والثقافةالإسلامية

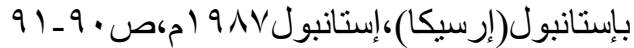

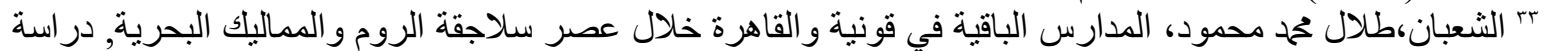

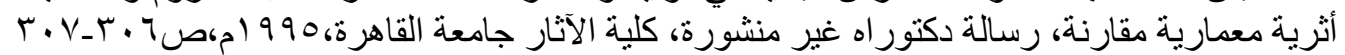

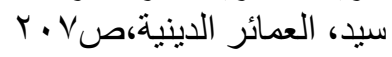

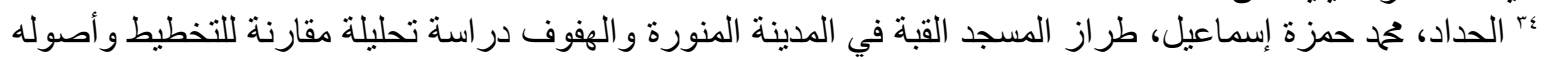

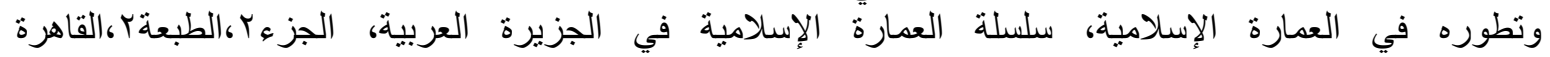
r.

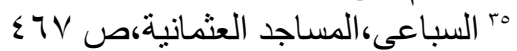
${ }^{36}$ Ameen, Ahmed, Islamic Architecture In Greece :Mosques, Bibliotheca Alexandrina, Center for Islamic Civilization Studies, 2017,pp110-115,154-159,171 